\title{
DNA methylation profiling reveals novel diagnostic biomarkers in renal cell carcinoma
}

\author{
Brittany N Lasseigne ${ }^{1,2}$, Todd C Burwell ${ }^{1}$, Mohini A Patil ${ }^{3}$, Devin M Absher ${ }^{1}$, James D Brooks ${ }^{3}$ \\ and Richard M Myers ${ }^{1 *}$
}

\begin{abstract}
Background: Renal cell carcinoma (RCC) is the tenth most commonly diagnosed cancer in the United States. While it is usually lethal when metastatic, RCC is successfully treated with surgery when tumors are confined to the kidney and have low tumor volume. Because most early stage renal tumors do not result in symptoms, there is a strong need for biomarkers that can be used to detect the presence of the cancer as well as to monitor patients during and after therapy.
\end{abstract}

Methods: We examined genome-wide DNA methylation alterations in renal cell carcinomas of diverse histologies and benign adjacent kidney tissues from 96 patients.

Results: We observed widespread methylation differences between tumors and benign adjacent tissues, particularly in immune-, G-protein coupled receptor-, and metabolism-related genes. Additionally, we identified a single panel of DNA methylation biomarkers that reliably distinguishes tumor from benign adjacent tissue in all of the most common kidney cancer histologic subtypes, and a second panel does the same specifically for clear cell renal cell carcinoma tumors. This set of biomarkers were validated independently with excellent performance characteristics in more than 1,000 tissues in The Cancer Genome Atlas clear cell, papillary, and chromophobe renal cell carcinoma datasets.

Conclusions: These DNA methylation profiles provide insights into the etiology of renal cell carcinoma and, most importantly, demonstrate clinically applicable biomarkers for use in early detection of kidney cancer.

Keywords: Cancer, Diagnostic biomarker, DNA methylation, Kidney, Renal cell carcinoma

\section{Background}

In 2013, approximately 65,000 cases of renal cell carcinoma (RCC) were diagnosed in the United States and 13,600 patients died of the disease. RCC incidence is rising by approximately 2 to $3 \%$ per year [1-4], in large part due to the increasing use of abdominal imaging [5]. Nearly half of all renal tumors are discovered incidentally [5,6], 20\% of small tumors (less than $4 \mathrm{~cm}$ ) are benign [7], and there are no imaging features or biomarkers that reliably distinguish benign from malignant disease [8]. For cancers confined to the kidney, the standard of care is resection, with high 5-year survival rates. Survival rates are directly correlated with tumor stage and size, demonstrating the

\footnotetext{
*Correspondence: rmyers@hudsonalpha.org

'HudsonAlpha Institute for Biotechnology, 601 Genome Way, Huntsville, AL 35806, USA

Full list of author information is available at the end of the article
}

importance of early detection of lesions when the lesions are small. Following tumor resection, patients must be monitored for recurrence at regular intervals by imaging studies (usually CT scanning), and thus incur significant radiation exposure with the attendant risks $[9,10]$. Once metastatic, RCC is usually fatal, despite treatment with targeted therapies, although a small fraction of patients show durable responses to IL-2 immunotherapy $[3,11,12]$.

RCC is classified into histological subtypes with distinct clinical and pathogenic features [13]. Clear cell renal cell carcinoma (ccRCC), the most clinically aggressive subtype, comprises $75 \%$ of cases and is characterized by inactivation of the von Hippel-Lindau ( $V H L)$ tumor suppressor gene, a regulator of oxygen sensing in the cell by controlling HIF1 $\alpha$ protein levels [14]. Papillary RCC (pRCC; $10 \%$ of cases) commonly has trisomy of chromosomes 7 and 17 and may be less clinically aggressive than ccRCC. 
Chromophobe carcinomas (chRCC) are the least aggressive tumors and comprise $5 \%$ of cases. Additionally, less common RCC subtypes arise from various cells of the nephron and present diverse clinical behavior [15]. Perhaps because of the histologic, molecular, genetic, and clinical diversity of RCC and its origin from different cell types in the nephron, biomarkers for use across the most common histologic subtypes types of RCC for detection or monitoring have not been previously reported.

Detection of DNA methylation at candidate loci in RCC suggests that tumor-specific methylation changes could be used diagnostically. However, the performance characteristics of these markers have limited their utility. Small studies have shown that simultaneous measurement of several differentially methylated loci could improve performance [16-18]. We hypothesized that better biomarkers could be identified by using genome-wide studies of DNA methylation in RCC. Such previous studies indicated that DNA methylation changes are early events in carcinogenesis, but these experiments were not designed to identify cancer-specific diagnostic biomarkers [19-24]. In this study, we profiled DNA methylation in tumor and adjacent normal tissue in 96 RCC patients with Illumina HumanMethylation27 microarrays. Using the predictive analysis of microarray (PAM) classification tool [25], we identified a biomarker panel capable of differentiating kidney tumors from benign adjacent kidney tissue, irrespective of tumor histology. This study provides insight into RCC etiology, presents validated tissue-based diagnostic biomarkers, and supplies a framework for the development of DNA methylation-based molecular diagnostics for RCC detection in patients.

\section{Methods}

\section{Sample collection and preparation}

Kidney samples used in this study were collected at Stanford University in accordance with approved institutional review board protocol (6208, Panel: 8) with patients' informed consent under protocols approved by the Stanford University and HudsonAlpha Institute for Biotechnology Institutional Review Board. Signed patient consent for use of kidney tissue states that clinical and pathological data can be associated with their clinical samples and tissue would otherwise be discarded after processing for clinical care. Consent forms are stored at Stanford University and available for review according to local, state, and federal regulations. Immediately after surgical removal of the kidney, fresh normal and tumor tissue samples were harvested, flash frozen in liquid nitrogen, and stored at $-80^{\circ} \mathrm{C}$ until they were used. For each sample, a frozen section was taken, stained with hematoxylin and eosin, and evaluated by a genitourinary pathologist. Normal samples were harvested distant from the tumor and confirmed by histology to have no contamination with malignant cells. Cancer samples were also confirmed to be enriched ( $>80 \%$ epithelial cells) for cancer cells relative to stroma. Cancer samples were macroscopically dissected to remove normal contamination and necrotic tissue using the hematoxylin and eosinstained sections as a guide.

Clinical information associated with each patient is summarized in Additional file 1: Table S1. We isolated DNA from fresh-frozen tissue samples using the QIAGEN AllPrep DNA kit (QIAGEN) following the manufacturer's protocol.

\section{Sodium bisulfite conversion and Illumina Infinium HumanMethylation27 assay}

We performed sodium bisulfite conversion of gDNA using the EZ-96 DNA Methylation Kit (Deep-well format, ZymoResearch) with the alternative incubation protocol for the Illumina Infinium Methylation Assay, as described by the manufacturer. We assayed $500 \mathrm{ng}$ of sodium bisulfite-converted gDNA from patient tissues by Infinium HumanMethylation27 RevB Beadchip Kits (Illumina) per the manufacturer's protocol.

\section{Beta score calculations, filtering, and batch normalization of methylation data}

We analyzed HumanMethylation27 array results using Illumina BeadStudio software with the Methylation Module v3.2. Any negative beta scores were converted to a zero and any beta scores with an associated detection $P$ value of $>0.01$ were converted to "NA" and filtered from analysis. To correct any array-by-array variation, we imputed all missing values with KNN Impute, followed by array batch normalization using the ComBat R-package [26]. Previously imputed values were converted back to "NA" for all further analyses. CpGs with "NA" in more than $10 \%$ of samples were removed from the data set. As previously reported, we removed CpGs with questionable mapping or those including a SNP of $>3 \%$ minor allele frequency within $15 \mathrm{bp}$ of the assayed $\mathrm{CpG}$ to avoid potential variation in probe hybridization [27]. After quality control and filtering, we had 96 patients with 26,148 CpGs assayed in both kidney tumor and benign adjacent tissues.

\section{Linear mixed and logistic regression analysis}

For the regression analysis we used RStudio (version 0.97.551) in $\mathrm{R}$ (version 3.0.0). For the linear mixed model analysis of the methylation data we used the lme command treating patients as a random effect and age and gender as fixed effects. We used the glm command with family set to binomial for the logistic regression of the diagnostic biomarkers. We selected our best model based on a maximum receiver operating characteristic (ROC) curve area and a minimum Akaike Information 
Criterion (AIC) value. All regression models have $P$ values adjusted for multiple hypothesis testing (false discovery rate, FDR) using the Benjamini and Hochberg (BH) algorithm and significant $\mathrm{CpGs}$ have an adjusted $P<0.05$.

\section{Hierarchical clustering}

Prior to hierarchical clustering, we mean-centered beta scores. We performed hierarchical clustering of the methylation data by both gene and array using Cluster 3.0 with average linkage [28].

\section{Prediction analysis of microarrays (PAM)}

We performed PamR (version 1.54) analysis on all filtered CpGs as described in the PamR manual with RStudio (version 0.97.551) in $\mathrm{R}$ (version 3.0.0) [25]. Based on visual examination of the training errors and cross-validation results, we minimized the miss-rate and set the shrinkage threshold to 10.74 for all tumor and benign adjacent normal classification, and 14.8 for clear cell tumor and benign adjacent normal classification.

\section{Gene ontology (GO)-term and gene set enrichment analysis (GSEA)}

We associated CpGs identified as significant with the closest gene and then those genes were analyzed for common pathways and functions. Terms reported have an adjusted (FDR) $P<0.05$. We performed GO-term analysis using the web version of GOrilla [29] and we performed GSEA using the web version of GSEA [30,31] with KEGG, BIOCARTA, and REACTOME gene sets selected.

\section{The Cancer Genome Atlas (TCGA) data}

We downloaded TCGA Illumina HumanMethylation27 and HumanMethylation450 Level 3 array results for all kidney cancer patients available at the time of manuscript preparation. Diagnostic biomarker validation for ccRCC patients utilized HumanMethylation27 tumor and matched benign adjacent normal ccRCC TCGA data only. Diagnostic biomarker validation for the general RCC patients utilized both HumanMethylation27 and HumanMethylation450 tumor and matched benign adjacent normal ccRCC, pRCC, and ChRCC TCGA data. We downloaded RNA expression data for ccRCC patients using the RNA-seq Level 3 data available at the time of manuscript preparation.

\section{Results}

Identification of differential methylation between kidney tumor tissue and benign adjacent kidney tissue

We collected clinical data, including histologic subtype, tumor grade and stage, and clinical follow-up, for 96 patients (Additional file 1: Table S1). We profiled DNA methylation of both kidney tumor and adjacent benign normal tissue from each patient by using
Illumina HumanMethylation27 arrays, which interrogate 27,578 CpGs located primarily in the promoter regions of genes in the human genome. After quality control and filtering, we performed DNA methylation analysis on results from 96 patients and 26,148 CpGs. Methylation at $127 \mathrm{CpGs}$ was validated in 19 of the benign adjacent kidney tissues with Bis-seq, as reported previously [32]; concordance was 0.82. Additionally, our group has previously validated this same platform with PyroMark in prostate cancer [27]. To identify CpGs carrying tumor-specific aberrant methylation, we performed linear mixed modeling with paired tumor/normal data at each CpG. Our models treated patient ID as a random effect and included gender and age as fixed effects. When we analyzed all CpGs and patients with these models, 9,800 CpGs were significantly different between kidney tumor and benign adjacent kidney tissue (FDR <0.05). Of these, 5,155 CpGs had increased methylation and 4,645 had decreased methylation in tumors compared to benign adjacent tissue (Additional file 1: Table S2).

Using the most significant CpGs from the linear mixed effects model $\left(1,172 \mathrm{CpGs}\right.$, FDR $\left.<1 \times 10^{-10}\right)$, we performed hierarchical clustering by sample and CpG (Figure 1). We observed one cluster with shorter branch lengths that contained all but three of the normal tissue samples (Figure 1). Most of the tumors were in the surrounding clusters and off-shoots with longer branch lengths, indicating greater heterogeneity in the tumor methylation profiles [33].

We performed a GSEA of the GO-terms and pathways associated with genes nearest CpGs exhibiting increased and decreased methylation in tumors compared to benign adjacent normal tissues (Additional file 1: Table S3) [29-31] to assist interpretation of significant findings. In the tumors, decreased methylation showed enrichment in genes associated with immune function and G-protein coupled receptor (GPCR) signaling. Previous reports have indicated upregulation of immune-related genes and suggested some of that deregulation might be explained by epigenetic changes [34]. Terms associated with increased methylation included cell-cell signaling and gated channel activity. Genes associated with GPCR signaling also showed increased methylation. While gene expression changes in GPCR signaling have been previously reported [35,36], to our knowledge, this is the first report of widespread differential methylation in genes related to GPCR signaling in RCC. Additionally, pathways associated with integration of energy metabolism, extracellular matrix organization, and WNT signaling were significantly enriched.

We repeated the regression analysis including only the 63 patients with ccRCC in our patient collection and found that about $85 \%$ of the differentially methylated CpGs continued to be significant (FDR <0.05) (Additional 


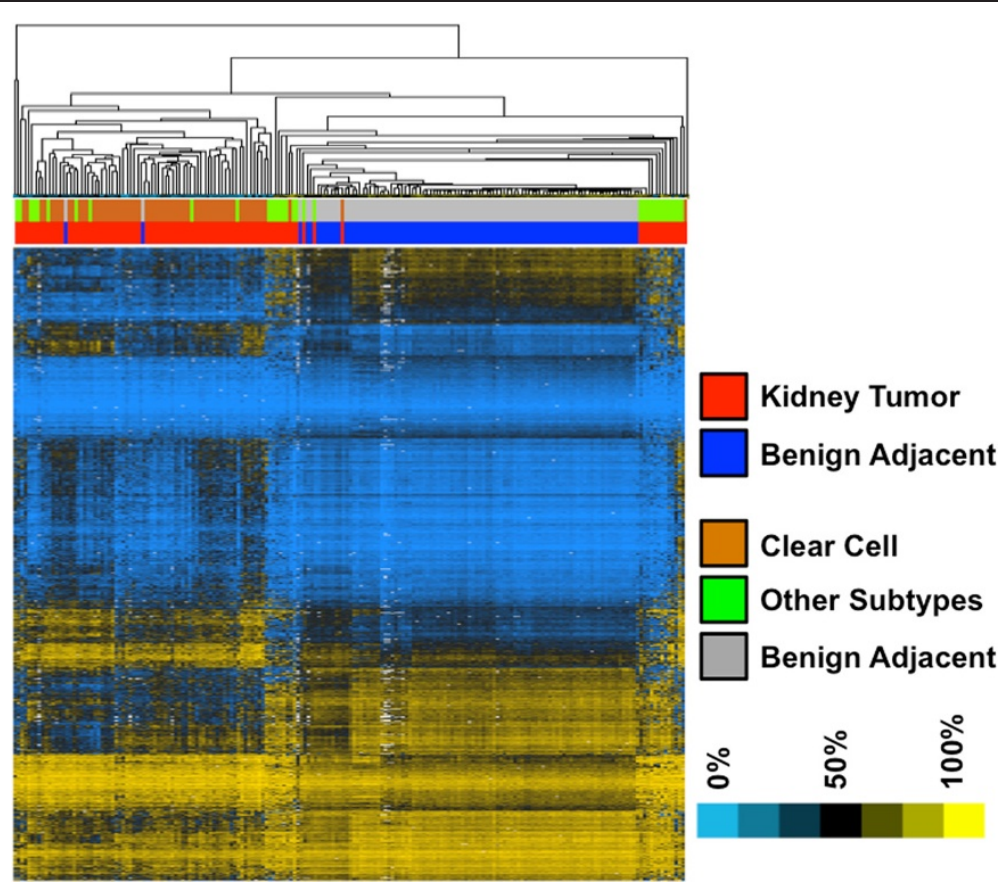

Figure 1 Hierarchical clustering of kidney tumor and benign adjacent tissues with most significant DNA methylation changes. Hierarchical clustering by both sample and CpG of 192 kidney tumor (red color bar) and kidney benign adjacent (blue color bar) tissues with linear mixed model significant CpGs (FDR $<1 \times 10^{-10} ; 1,172 \mathrm{CpGs}$ ); (blue pixels) low DNA methylation; (yellow pixels) high DNA methylation; (orange color bar) cCRCC tissues; (green color bar) other subtype RCC tissues; (grey color bar) benign adjacent tissues.

file 1: Table S2). These included CpG loci near $V H L$, SETD2, BAP1, and UQCRH, all genes previously shown to be mutated in RCC patients [37,38]. However, we did not see significant DNA methylation changes for PBRM1, a gene previously shown to have truncating mutations in RCC at a level superseded only by VHL [38]. Likewise, a gene set enrichment and GO-term analysis of the significantly altered CpGs in the ccRCC specimens revealed functions and pathways very similar to the results we obtained when analyzing all 96 of the tumors in our study set (Additional file 1: Table S3).

\section{Diagnostic methylation markers}

We used PAM to identify a set of markers that best distinguished normal from malignant kidney samples [25,27]. PAM uses a shrunken centroid classification algorithm to identify significant CpGs whose methylation distinguishes tumor tissue from benign adjacent tissue. When all 192 tissues were included in the analysis, we identified 20 CpGs that discriminated between benign adjacent tissue and tumor tissue (Additional file 1: Table S4). Using this list of $20 \mathrm{CpGs}$, we performed hierarchical clustering on both the samples and CpGs (Figure 2, panel A). Visual inspection showed that 91 of 96 tumors cluster together and 93 of 96 benign adjacent normal tissues cluster together. Nineteen of these $20 \mathrm{CpGs}$ were significant in our linear mixed model analysis of CpGs that are differentially methylated between tumor and benign adjacent kidney tissue (FDR <0.05).

When we repeated this analysis with only the 63 ccRCC patient specimens, PAM identified 11 CpGs that discriminated between benign adjacent and tumor tissues (Additional file 1: Table S4). Hierarchical clustering on both the samples and the CpGs (Figure 2, panel B) showed almost perfect classification with only one tumor sample clustering with the benign adjacent normal tissues. These 11 CpGs were also significant in our linear mixed model analysis of the ccRCC tumor data and the benign adjacent normal data (FDR <0.05). The better classification of the ccRCCs compared to all of the subtypes was most likely because of the greater heterogeneity in the DNA methylation profiles between all of the subtypes. There were 4 CpGs that overlapped between the ccRCC and all tumor CpG loci identified by PAM.

Using our data as a training set, we built a logistic regression model from the PAM diagnostic list capable of discriminating between tumor and benign adjacent tissues. From the $20 \mathrm{CpG}$ panel for the multiple subtype PAM list, we selected a model with the greatest ROC area under the curve (AUC) and an AIC at a local minima compared to models with 1 to 20 CpGs. This 5 CpG model (comprised of cg13156411, cg14456683, cg18003231, cg12782180, and cg22719623) had a ROC area of 0.991 and a $\mathrm{BH}$-adjusted highly significant $P$ value of $8.10 \times 10^{-31}$ 

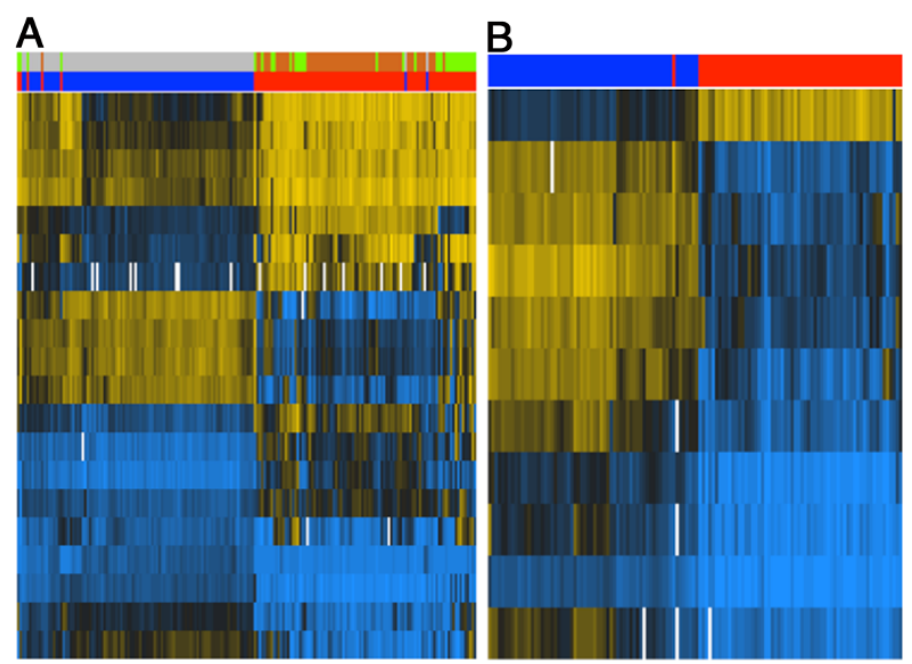

\section{$\square$ Kidney Tumor

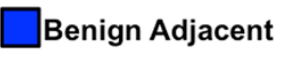

\section{$\square$ clear Cell}

$\square$ Other Subtypes

$\square$ Benign Adjacent

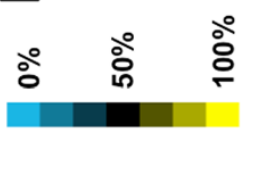

Figure 2 Hierarchical clustering of kidney tumor and kidney benign adjacent tissues with PAM classifier panel CpGs. (A) Hierarchical clustering by both sample and CpG of all 192 kidney tumor and kidney benign adjacent tissues with PAM classifier panel CpGs (20 CpGs). (B) Hierarchical clustering by both sample and CpG of 126 clear cell kidney tumor and kidney benign adjacent tissues with PAM classifier panel CpGs (11 CpGs); (blue pixels) low DNA methylation; (yellow pixels) high DNA methylation; (red color bar) tumor tissues; (orange color bar) ccRCC tissues; (green color bar) other subtype RCC tissues; (blue/grey color bar) benign adjacent tissues.

for the null hypothesis that the ROC curve area is 0.5 (which would indicate that a model would not discriminate between tumor and benign adjacent tissue).

We used publicly available renal cell carcinoma genomic data from TCGA as a validation test set for our predictive model. TCGA has DNA methylation data available for 732 RCC (ccRCC, papillary, and chromophobe) tissues and 410 normal kidney tissues. When we applied our 5 CpG model to all of the TCGA samples (Additional file 2: Figure S1), the ROC AUC was 0.990 and we correctly predict $87.8 \%$ of the normal and $96.2 \%$ of the tumor tissues (Figure 3, panel A). When this model was applied to each histologic subtype of kidney cancer and the normal tissues $(\mathrm{n}=410)$, the ROC AUC remained outstanding in all tumor types. For ccRCC $(n=509)$, the AUC was 0.98, and we correctly predicted $96.1 \%$ of the tumor samples (Figure 3, panel B). For pRCC $(n=157)$, the ROC AUC was 0.97 and we correctly predicted $94.9 \%$ of the tumor samples (Figure 3, panel C). The ROC AUC for chRCC $(\mathrm{n}=66)$ was 0.99 and we correctly predicted $100 \%$ of the tumor tissues (Figure 3, panel D). Model sensitivity was largely independent of cancer stage and primary tumor size (Additional file 1: Table S5).

When the ccRCC patients were analyzed separately, 4. CpGs (cg04511534, cg11098259, cg14391855, and cg26366091) produced a ROC AUC of 0.990 with a $\mathrm{BH}$-adjusted $P=1.46 \times 10^{-20}$ for the null hypothesis that the ROC AUC is 0.5. In TCGA specimens (208 tumor tissues and 200 normal tissues), the 4. CpG model showed an AUC of 0.972 (Figure 4, Panel A) and we correctly identified $91.4 \%$ of the tumors and $98.9 \%$ of the benign adjacent tissues. Model sensitivity remained high regardless of cancer stage and primary tumor size (Additional file 1: Table S6). A comparison of the DNA methylation differences between tumor and benign adjacent normal tissues demonstrated good agreement between our and the TCGA datasets. For example, at cg04511534, we saw no statistical difference between our data and TCGA data $(P=0.25$ and 0.18$)$; however, the difference between tumor and normal was consistent between the two data sets $(P<0.0001)$ (Figure 4, Panel B) (Additional file 2: Figure S1).

RNA-seq expression data was available for a subset of ccRCC patients in the TCGA data, allowing us to investigate whether the changes in DNA methylation we observed are correlated with transcript levels at nearby genes. In 9 of 11 genes, significantly different levels of gene expression were observed in the gene closest to the significant CpG (Mann-Whitney test, $P<0.05$ ) in the expected direction based on methylation status. For example, cg04511534, located in the first intron of the gene encoding gamma-glutamyltransferase 6 (GGT6), is hypermethylated in tumors compared to normal tissues. Transcript levels of GGT6 were significantly decreased in the tumor samples compared to the normal tissues (MannWhitney, $P<0.0001$; Figure 4, Panel C) (Additional file 3: Figure S2). The relationship between cg04511534 DNA methylation and GGT6 expression shows significant correlation, following the expected canonical model of increased DNA methylation in the tumors leading to decreased expression (linear regression, $P<0.0001 ; \mathrm{R}^{2}=$ 0.503; Figure 4, Panel D). For the other $10 \mathrm{CpGs}$ from the diagnostic panel and the genes to which they are near, we found a range of $P$ values $(0.0001$ to 0.8540$)$ and $R^{2}$ values $(0.0001671$ to 0.503$)$, with significant correlation 

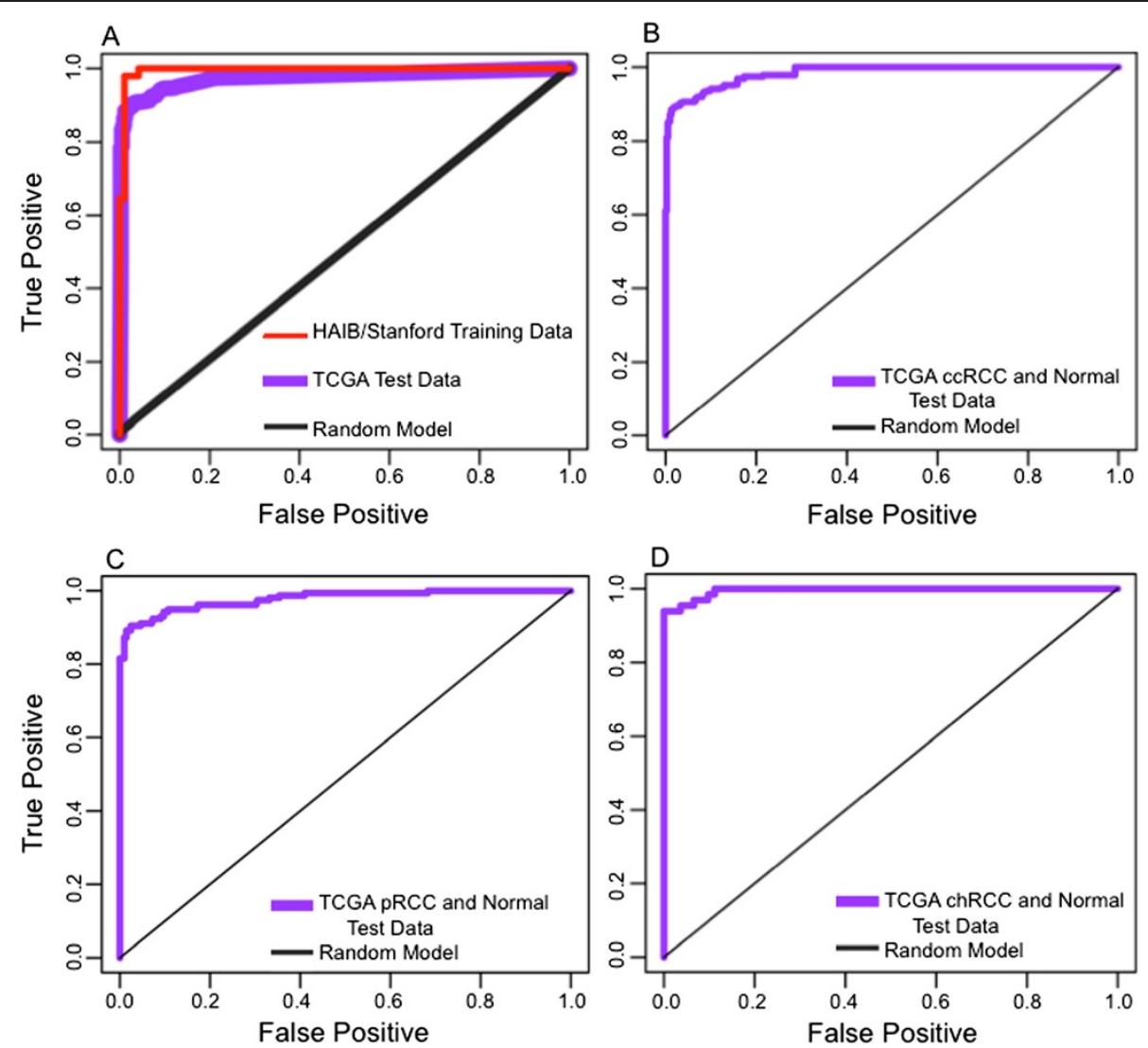

Figure 3 PAM diagnostic panel model for renal cell carcinoma. (A) ROC curve of best 5 CpG model (Benjamini and Hochberg-adjusted $P=8.10 \times 10^{-31}$ ) from PAM diagnostic panel produced via the HudsonAlpha/Stanford data (ROC AUC =0.991), and applied to the TCGA data (ROC AUC = 0.990). (B) ROC curve of best 5 CpG model applied to TCGA cCRCC and normal kidney tissue data (ROC AUC =0.98). (C) ROC curve of best 5 CpG model applied to TCGA pRCC and normal kidney tissue data (ROC AUC $=0.97$ ). (D) ROC curve of best 5 CpG model applied to TCGA chRCC and normal kidney tissue data (ROC AUC $=0.99$ ). Random model is 50 random draws of 5 non-significant training set $C p G s$.

between RNA expression and DNA methylation in 8 of 11 pairs.

\section{Discussion}

We found large scale, genome-wide changes in 5methylcytosine encompassing 9,800 CpGs that differentiated malignant from normal kidney tissues. Furthermore, we developed a panel of $20 \mathrm{CpGs}$ that can discriminate ccRCC, pRCC, and chRCC from normal renal tissue, as well as a panel of 11 CpGs that discriminate between ccRCC tumor and normal tissues. These methylation differences were validated independently in TCGA data and retained high sensitivity and specificity for distinguishing malignant from adjacent normal tissue for all three histologic subtypes. Because of the high sensitivity and specificity of our biomarkers in both data sets, these panels are strong candidates for development of a clinical test for detection of all three major histologic types of RCC.

The candidate biomarkers we identified were all located in the promoter regions or first introns of nearby genes, many of which are interesting in RCC. For example, our most predictive $\mathrm{CpG}$ is in the first intron of gamma-glutamyltransferase 6 (GGT6). GGT6 participates in leukotriene synthesis, glutathione metabolism, and gamma-glutamyl transfer. GGT6 has been linked to immune infiltration and inflammation and putatively to alterations in DNA methylation via changing levels of glutathione and methyl group availability $[39,40]$. Other CpGs are associated with genes related to immune function, including $\mathrm{T}$ cell regulation and inflammation, tumor initiation and angiogenesis (EBI3) [41,42], while other genes have been implicated in cancer aggressiveness (AQP9, RIN1) [43-47].

Some panel CpGs are in the promoters of genes previously implicated as biomarkers, or involved in carcinogenesis, cancer progression, or treatment response. For example, $P E N K$ promoter methylation was demonstrated in prostate cancer, breast cancer brain metastasis, and pulmonary adenocarcinoma, and as a potential methylation biomarker for colorectal, meningioma, and bladder cancer [48-53]. KLK10 promoter methylation has been implicated in head and neck squamous cell carcinoma 

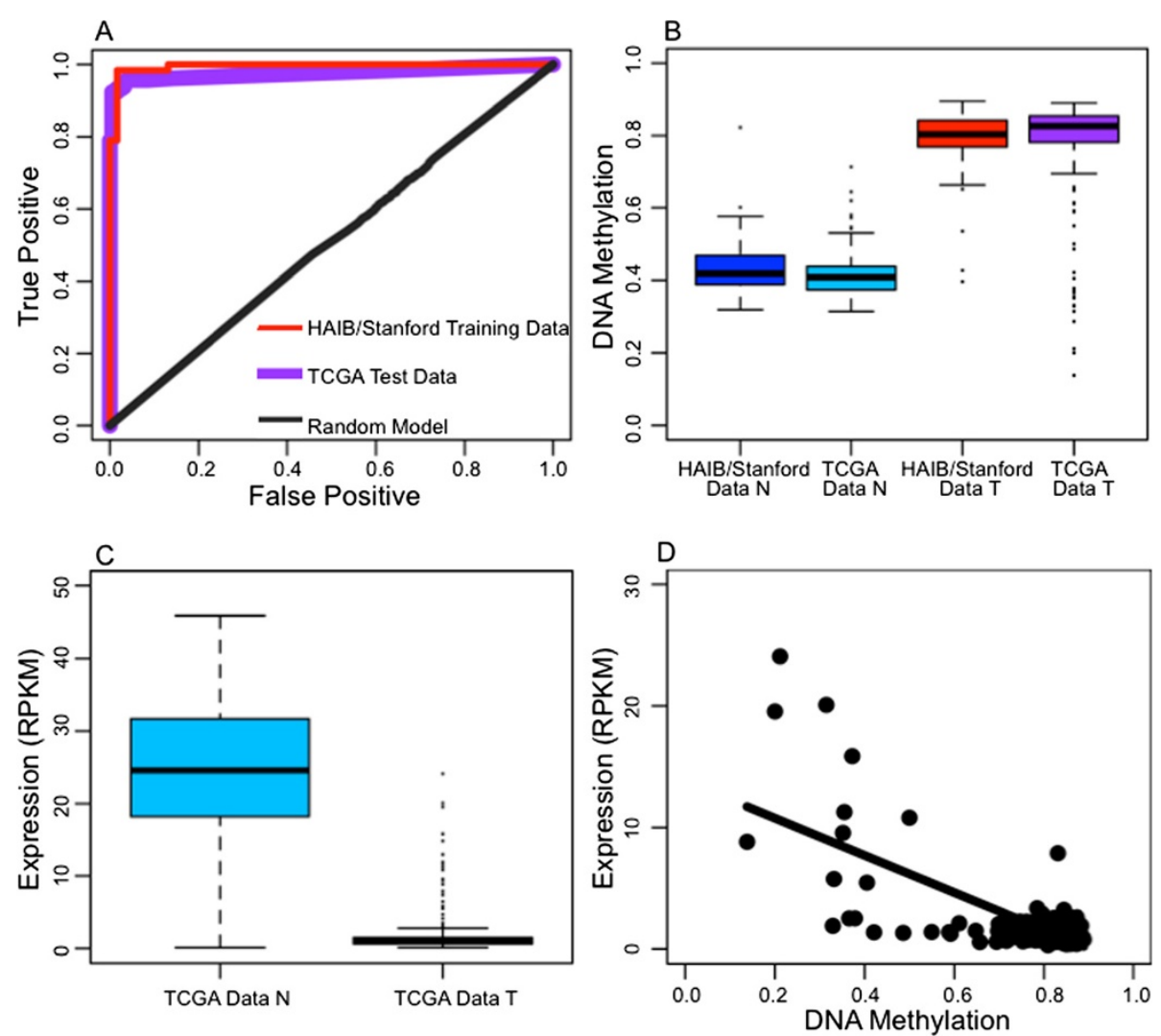

Figure 4 PAM diagnostic panel model for clear cell renal cell carcinoma. (A) ROC curve of best 4 CpG model (Benjamini and Hochbergadjusted $P=1.46 \times 10^{-20}$ ) from PAM diagnostic panel produced in the HudsonAlpha/Stanford data (ROC AUC $\left.=0.990\right)$ and applied to TCGA (ROC AUC = 0.972). (B) DNA methylation at cg04511534, a CpG in the most predictive HudsonAlpha/Stanford model (Mann-Whitney test; Bonferroniadjusted $P=0.2524$ for HudsonAlpha/Stanford normal tissues versus TCGA normal tissues; Bonferroni-adjusted $P=0.1848$ for HudsonAlpha/ Stanford tumor tissues versus TCGA tumor tissues; Bonferroni-adjusted $P<0.0001$ for HudsonAlpha/Stanford normal tissues versus TCGA tumor tissues, Bonferroni-adjusted $P<0.0001$ for HudsonAlpha/Stanford tumor tissues versus TCGA normal tissues). (C) Expression of GGT6 in TCGA tumor and normal tissue data (Mann-Whitney test; $P$ <0.0001). (D) GGT6 expression versus cg04511534 methylation in TCGA tumor tissue data (linear regression; $P<0.0001, R^{2}=0.5030$ ). Random model is 50 random draws of 5 non-significant training set CpGs.

progression, as well as a potential prostate cancer and non-small cell lung cancer biomarker [54-56]. ZIC1 was implicated as a tumor suppressor silenced via promoter methylation in malignant pleural mesothelioma and gastric cancer [57,58]. ZIC1 promoter methylation has also been suggested as a potential prognostic marker in ovarian cancer [59]. Additionally, C21ORF123 promoter methylation has been implicated in cisplatin resistance in non-small cell lung cancer and RIN1 is a tumor suppressor that is deregulated through aberrant promoter methylation in breast cancer $[60,61]$. Interestingly, one of the CpGs showing decreased DNA methylation in tumors is in the promoter of serum amyloid A1 (SAA1), which has been previously implicated in RCC. SAA1 is highly expressed during inflammation and has been identified as a potential Wilms' tumor marker [62], as one of a two-protein signature model for prognosis prediction in metastatic RCC [63], and as a predictor in fatal outcome in RCC [64].
While it is possible that additional genomic biomarkers could be identified with higher resolution methylation assays, the exceptional performance of these biomarkers in training and test sets, as well as their ability to identify RCC tumors of diverse histology, make them outstanding candidates for development of clinical grade assays. As an increasing number of small renal lesions are being detected through cross-sectional imaging, targeted biopsies of lesions are used to determine whether these lesions are malignant or benign. An assay based on detection of methylated sequences could find immediate application in these diagnostic renal biopsies. However, in a significant fraction of biopsies, insufficient tissue is obtained for histologic diagnosis of malignancy and a genomic assay incorporating our methylation loci could be useful for detecting malignant cells in small biopsies. Furthermore, detection of these methylated sequences could be deployed as a non-invasive detection test in patient blood or urine. Measurement of differential genomic marks in patient 
blood and urine has already proven useful for diagnosis of cancer in the clinical setting. For example, differential methylation of Sept9 in patient blood is used for diagnosis of colorectal cancer $[65,66]$ and detection of the non-coding RNA PCA3 in patient urine is used for risk assessment of prostate cancer [67-70]. In RCC of all types, a blood or urine assay could be used for early detection in high risk populations, for monitoring patients after definitive surgical treatment, or possibly in monitoring response to therapy in patients with advanced disease.

Additional work will be necessary to evaluate the performance of these methylation markers in less common RCC histologies, as well as benign entities such as angiomyolipoma or hemorrhagic cysts. Further investigation of the consequences of DNA methylation at these predictive loci, including assessments of gene expression and other DNA alterations, could provide insights into important biological processes common to ccRCC, pRCC, and chRCC.

\section{Conclusions}

RCC survival rates are directly correlated with tumor stage and size and, once metastatic, RCC is usually fatal, demonstrating the importance of early detection when lesions are small. However, RCC tumors are difficult to diagnose because of non-specific symptoms and a reliance on imaging technologies. Due to the molecular and clinical diversity of RCC, biomarkers for use across the most common histologic subtypes of RCC for detection or monitoring have not been previously reported. We have discovered and validated a DNA methylation biomarker panel that is capable of differentiating kidney tumor from benign adjacent kidney tissue, irrespective of tumor histology and with high sensitivity and specificity across all tumor stages. These biomarkers could potentially aide in early clinical detection of kidney cancer, distinguishing between benign and malignant lesions, and monitoring patients after therapy.

\section{Additional files}

Additional file 1: Table S1. Clinical information associated with kidney patients. For each patient, Tumor ID\# (unique identification ID for tumor tissue sample), Normal ID\# (unique identification ID for benign adjacent normal tissue sample), Age (patient age at time of resection), Gender, Surg type (surgical type for tissue resection), Tumor type, Grade, Stage, Margins, Tumor size (in centimeters), Recurrence status, Status code, Time FU event (time to follow-up event after surgery, in months), and Time death (time to death after surgery, in months). Table S2. Significant linear mixed model analysis results. For each $\mathrm{CpG}$ significant in a linear mixed model analysis of the methylation data treating patient as a random effect and age and gender as fixed effects (FDR <0.05), the CpG and which model it was significant in are reported. Table S3. Significant GO and GSEA terms (adjusted $P<0.05$ ) for genes identified in linear mixed model analysis. For each significant GO and GSEA term identified from the linear mixed model analysis, the term identifier, term description, the model the term was significant for, and whether the term was significant for genes associated with CpGs with increasing or decreasing methylation in tumors compared to benign adjacent normal is reported. Table S4. Significant CpGs by PAM analysis. For each CpG significant in the PAM analysis, the cancer type the CpG was significant for, and the associated gene is reported. Table S5. Model sensitivity by cancer stage for five CpG multiple cancer models. For each cancer subtype, model sensitivity was calculated by stage for TCGA patients. Asterisks $\left(^{*}\right)$ indicate the inclusion of patients in the total without a specified cancer stage: ccRCC $(n=11)$, pRCC $(n=38)$, chRCC $(n=2)$, and total $(n=51)$. Model sensitivity in tumors smaller than $4 \mathrm{~cm}$ (T1a) was also calculated for each subtype: $\operatorname{ccRCC}(0.92, n=125)$, $\operatorname{pRCC}(0.92, n=37)$, chRCC $(1.00, n=5)$, and total $(0.92, n=167)$. Table S6. Model sensitivity by cancer stage for four CpG ccRCC model. Model sensitivity was calculated by stage for TCGA patients. Model sensitivity in tumors smaller than $4 \mathrm{~cm}(T 1 a)$ was also calculated $(0.86, \mathrm{n}=50)$.

Additional file 2: Figure S1. Remaining diagnostic panel biomarker $\mathrm{CpG}$ values from models. DNA methylation of the five CpGs in both HudsonAlpha/Stanford patients and TCGA patients in the best RCC diagnostic model (cg13156411, cg14456683, cg18003231, cg12782180, and cg12782180; panel A-E), and the other three CpGs in both HudsonAlpha/Stanford patient and TCGA patients in the best cCRCC diagnostic model (cg11098259, cg14391855, and cg26366091; panel F-H). In all panels, HudsonAlpha/Stanford Data N versus HudsonAlpha/Stanford Data T and TCGA Data N versus TCGA Data T comparisons are significant (Mann-Whitney test; Bonferroni-adjusted $P<0.0001$ ).

Additional file 3: Figure S2. RNA expression values for genes nearest other three predictive CpGs in ccRCC. RNA expression of the three other genes in TCGA patients in the best ccRCC diagnostic model (panel A-C, Mann-Whitney test; $P<0.0001)$. The $\mathrm{CpGs}$ are all in the promoter regions of the respective genes (cg11098259 and AQP9; $c g 14391855$ and RIN1; cg26366091 and CHI3L2; panel A-C).

\section{Abbreviations}

AIC: Akaike information criterion; AUC: Area Under Curve; BH: BenjaminiHochberg; ccRCC: Clear cell renal cell carcinoma; chRCC: Chromophobe renal cell carcinoma; FDR: False discovery rate; GGT6: Gamma-glutamyltransferase 6; GO: Gene ontology; GPCR: G-protein coupled receptor; GSEA: Gene set enrichment analysis; PAM: Probability Analysis of Microarrays; pRCC: Papillary renal cell carcinoma; RCC: Renal cell carcinoma; ROC: Receiver operating characteristic; TCGA: The Cancer Genome Atlas; VHL: von Hippel-Lindau.

\section{Competing interests}

The authors declare that they have no competing interests.

\section{Authors' contributions}

BNL, DMA, JDB, and RMM designed the experiments. JDB and MAP prepared tissue samples. BNL and DMA collected data and performed experiments for the study. BNL, TCB, DMA, JDB, and RMM analyzed the data. BNL wrote the first draft of the paper. BNL, TCB, DMA, JDB, and RMM contributed to writing of the paper. All authors read and approved the final manuscript.

\section{Acknowledgements}

We thank Kevin Roberts, Krista Stanton, and Lindsay Waite Jones for help with the HumanMethylation27 assays; Preti Jain for ComBat normalization of the data; Kenneth Day, Kevin Bowling, Marie Kirby, and Sara Cooper for stimulating discussions and critical reading of the manuscript. The authors also thank Dr. Jesse McKenney for histologic review of the kidney tumor and normal specimens. We acknowledge use of The Cancer Genome Atlas project $c C R C C$, pRCC, and chRCC data sets, which were extremely valuable in validating our findings. This project was funded by an award from The Daniel Foundation, by the HudsonAlpha Institute for Biotechnology, and by the NIH Early Detection Research Network (1U01CA152737-01).

\section{Author details}

${ }^{1}$ HudsonAlpha Institute for Biotechnology, 601 Genome Way, Huntsville, AL 35806, USA. ${ }^{2}$ Department of Biological Sciences, University of Alabama in Huntsville, Shelby Center for Science and Technology, Room 369, 301 Sparkman Drive, Huntsville, Alabama 35899, USA. ${ }^{3}$ Department of Urology, Stanford University, 875 Blake Wilbur Dr. Clinic E, Stanford, California 94305-5118, USA. 
Received: 15 July 2014 Accepted: 12 November 2014

Published online: 04 December 2014

\section{References}

1. Ferlay J, Shin H-R, Bray F, Forman D, Mathers C, Parkin DM: Estimates of worldwide burden of cancer in 2008: GLOBOCAN 2008. Int J Cancer 2010, 127:2893-2917.

2. Chow W-HWH, Devesa SS, Warren JL, Fraumeni JF: Rising Incidence of Renal Cell Cancer in the United States. JAMA 1999, 281:1628-1631.

3. Howlader N, Noone AM, Krapcho M, Neyman N, Aminou R, Altekruse SF, Kosary CL, Ruhl J, Tatalovich Z, Cho H, Mariotto A, Eisner MP, Lewis DR, Chen HS, Feuer EJ CK (Eds): SEER Cancer Statistics Review. Bethesda, MD: National Cancer Institute; 2009.

4. Bhatt JR, Finelli A: Landmarks in the diagnosis and treatment of renal cell carcinoma. Nat Rev Urol 2014, 11:517-525.

5. Lightfoot N, Conlon M, Kreiger N, Bissett R, Desai M, Warde P, Prichard HM: Impact of noninvasive imaging on increased incidental detection of renal cell carcinoma. Eur Urol 2000, 37:521-527.

6. Silverman SG, Israel GM, Herts BR, Richie JP: Management of the incidental renal mass. Radiology 2008, 249:16-31.

7. Jeon HG, Lee SR, Kim KH, Oh YT, Cho NH, Rha KH, Yang SC, Han WK: Benign lesions after partial nephrectomy for presumed renal cell carcinoma in masses $4 \mathrm{~cm}$ or less: prevalence and predictors in Korean patients. Urology 2010, 76:574-579.

8. Bradley AJ, Lim YY, Singh FM: Imaging features, follow-up, and management of incidentally detected renal lesions. Clin Radiol 2011, 66:1129-1139

9. Lipsky MJ, Shapiro EY, Hruby GW, McKiernan JM: Diagnostic radiation exposure during surveillance in patients with pT1a renal cell carcinoma. Urology 2013, 81:1190-1195.

10. Sodickson A, Baeyens PF, Andriole KP, Prevedello LM, Nawfel RD, Hanson R, Khorasani $\mathrm{R}$ : Recurrent $\mathrm{CT}$, cumulative radiation exposure, and associated radiation-induced cancer risks from CT of adults. Radiology 2009, 251:175-184.

11. Jonasch E, Futreal PA, Davis IJ, Bailey ST, Kim WY, Brugarolas J, Giaccia AJ, Kurban G, Pause A, Frydman J, Zurita AJ, Rini BI, Sharma P, Atkins MB, Walker $\mathrm{CL}$, Rathmell WK: State of the science: an update on renal cell carcinoma. Mol Cancer Res 2012, 10:859-880.

12. Bielecka ZF, Czarnecka AM, Szczylik C: Genomic analysis as the first step toward personalized treatment in renal cell carcinoma. Front Oncol 2014, 4:194.

13. Rini BI, Campbell SC, Escudier B: Renal cell carcinoma. Lancet 2009, 373:1119-1132.

14. Kim WY, Kaelin WG: Role of VHL gene mutation in human cancer. J Clin Oncol 2004, 22:4991-5004.

15. Lopez-Beltran A, Carrasco JC, Cheng L, Scarpelli M, Kirkali Z, Montironi R: Update on the classification of renal epithelial tumors in adults. Int J Urol 2009, 2009:432-443.

16. Battagli C, Uzzo RG, Dulaimi E, Ibanez de Caceres I, Krassenstein R, Al-Saleem T, Greenberg RE, Cairns P: Promoter hypermethylation of tumor suppressor genes in urine from kidney cancer patients. Cancer Res 2003, 63:8695-8699.

17. Hoque MO, Begum S, Topaloglu O, Jeronimo C, Mambo E, Westra WH, Califano J, Sidransky D: Quantitative detection of promoter hypermethylation of multiple genes in the tumor, urine, and serum DNA of patients with renal cancer. Cancer Res 2004, 64:5511-5517.

18. Hauser S, Zahalka T, Fechner G, Müller SC, Ellinger J: Serum DNA hypermethylation in patients with kidney cancer: results of a prospective study. Anticancer Res 2013, 33:4651-4656.

19. Arai $E$, Chiku S, Mori T, Gotoh M, Nakagawa T, Fujimoto H, Kanai Y: Single-CpG-resolution methylome analysis identifies clinicopathologically aggressive CpG island methylator phenotype clear cell renal cell carcinomas. Carcinogenesis 2012, 33:1487-1493.

20. Arai E, Wakai-Ushijima S, Fujimoto H, Hosoda F, Shibata T, Kondo T, Yokoi S, Imoto I, Inazawa J, Hirohashi S, Kanai Y: Genome-wide DNA methylation profiles in renal tumors of various histological subtypes and non-tumorous renal tissues. Pathobiology 2011, 78:1-9.

21. Arai E, Ushijima S, Tsuda H: Genetic clustering of clear cell renal cell carcinoma based on array-comparative genomic hybridization: its association with DNA methylation alteration and patient outcome genetic clustering of clear cell renal cell carcinoma based on. Clin Cancer Res 2008, 14:5531-5539.

22. Morris MR, Ricketts CJ, Gentle D, McRonald F, Carli N, Khalili H, Brown M, Kishida T, Yao M, Banks RE, Clarke N, Latif F, Maher ER: Genome-wide methylation analysis identifies epigenetically inactivated candidate tumour suppressor genes in renal cell carcinoma. Oncogene 2011, 30:1390-1401.

23. McRonald FE, Morris MR, Gentle D, Winchester L, Baban D, Ragoussis J Clarke NW, Brown MD, Kishida T, Yao M, Latif F, Maher ER: CpG methylation profiling in VHL related and VHL unrelated renal cell carcinoma. Mol Cancer 2009, 8:31.

24. Creighton CJ, Morgan M, Gunaratne PH, Wheeler DA, Gibbs RA, Gordon Robertson A, Chu A, Beroukhim R, Cibulskis K, Signoretti S, Vandin Hsin-Ta Wu F, Raphael BJ, Verhaak RGW, Tamboli P, Torres-Garcia W, Akbani R, Weinstein JN, Reuter V, Hsieh JJ, Rose Brannon A, Ari Hakimi A, Jacobsen A, Ciriello G, Reva B, Ricketts CJ, Marston Linehan W, Stuart JM, Kimryn Rathmell W, Shen H, Laird PW, et al: Comprehensive molecular characterization of clear cell renal cell carcinoma. Nature 2013, 499:43-49.

25. Tibshirani R, Hastie T, Narasimhan B, Chu G: Diagnosis of multiple cancer types by shrunken centroids of gene expression. Proc Natl Acad Sci U S A 2002, 99:6567-6572.

26. Johnson $W E$, Li C, Rabinovic A: Adjusting batch effects in microarray expression data using empirical Bayes methods. Biostatistics 2007, 8:118-127.

27. Kobayashi Y, Absher DM, Gulzar ZG, Young SR, Mckenney JK, Peehl DM, Brooks JD, Myers RM, Sherlock G: DNA methylation profiling reveals novel biomarkers and important roles for DNA methyltransferases in prostate cancer. Genome Res 2011, 21:1017-1027.

28. Eisen MB, Spellman PT, Brown PO, Botstein D: Cluster analysis and display of genome-wide expression patterns. Proc Natl Acad Sci U S A 1998, 95:14863-14868.

29. Eden E, Navon R, Steinfeld I, Lipson D, Yakhini Z: GOrilla: a tool for discovery and visualization of enriched GO terms in ranked gene lists. BMC Bioinformatics 2009, 10:48.

30. Mootha VK, Lindgren CM, Eriksson K-F, Subramanian A, Sihag S, Lehar J, Puigserver P, Carlsson E, Ridderstråle M, Laurila E, Houstis N, Daly MJ, Patterson N, Mesirov JP, Golub TR, Tamayo P, Spiegelman B, Lander ES, Hirschhorn JN, Altshuler D, Groop LC: PGC-1alpha-responsive genes involved in oxidative phosphorylation are coordinately downregulated in human diabetes. Nat Genet 2003, 34:267-273.

31. Subramanian A, Tamayo P, Mootha VK, Mukherjee S, Ebert BL, Gillette MA, Paulovich A, Pomeroy SL, Golub TR, Lander ES, Mesirov JP: Gene set enrichment analysis: a knowledge-based approach for interpreting genome-wide expression profiles. Proc Natl Acad Sci U S A 2005, 102:15545-15550.

32. Day K, Waite LL, Thalacker-Mercer A, West A, Bamman MM, Brooks JD, Myers RM, Absher D: Differential DNA methylation with age displays both common and dynamic features across human tissues that are influenced by CpG landscape. Genome Biol 2013, 14:R102.

33. Gerlinger M, Rowan AJ, Horswell S, Larkin J, Endesfelder D, Gronroos E, Martinez P, Matthews N, Stewart A, Tarpey P, Varela I, Phillimore B, Begum S, McDonald NQ, Butler A, Jones D, Raine K, Latimer C, Santos CR, Nohadani M, Eklund AC, Spencer-Dene B, Clark G, Pickering L, Stamp G, Gore M, Szallasi Z, Downward J, Futreal PA, Swanton C: Intratumor heterogeneity and branched evolution revealed by multiregion sequencing. $N$ Engl J Med 2012, 366:883-892.

34. Wozniak MB, Le Calvez-Kelm F, Abedi-Ardekani B, Byrnes G, Durand G, Carreira C, Michelon J, Janout V, Holcatova I, Foretova L, Brisuda A, Lesueur F, McKay J, Brennan P, Scelo G: Integrative genome-wide gene expression profiling of clear cell renal cell carcinoma in Czech Republic and in the United States. PLoS One 2013, 8:e57886.

35. Dalgin GS, Holloway DT, Liou LS, DeLisi C: Identification and characterization of renal cell carcinoma gene markers. Cancer Inform 2007, 3:65-92

36. Zeng Z, Que T, Zhang J, Hu Y: A study exploring critical pathways in clear cell renal cell carcinoma. Exp Ther Med 2014, 7:121-130.

37. Dalgliesh GL, Furge K, Greenman C, Chen L, Bignell G, Butler A, Davies H, Edkins S, Hardy C, Latimer C, Teague J, Andrews J, Barthorpe S, Beare D, Buck G, Campbell PJ, Forbes S, Jia M, Jones D, Knott H, Kok CY, Lau KW, Leroy C, Lin M-L, McBride DJ, Maddison M, Maguire S, McLay K, Menzies A, 
Mironenko T, et al: Systematic sequencing of renal carcinoma reveals inactivation of histone modifying genes. Nature 2010, 463:360-363.

38. Varela I, Tarpey P, Raine K, Huang D, Ong CK, Stephens P, Davies H, Jones D, Lin M-L, Teague J, Bignell G, Butler A, Cho J, Dalgliesh GL, Galappaththige D, Greenman C, Hardy C, Jia M, Latimer C, Lau KW, Marshall J, McLaren S, Menzies A, Mudie L, Stebbings L, Largaespada DA, Wessels LFA, Richard S, Kahnoski RJ, Anema J, et al: Exome sequencing identifies frequent mutation of the SWI/SNF complex gene PBRM1 in renal carcinoma. Nature 2011, 469:539-542.

39. Heisterkamp N, Groffen J, Warburton D, Sneddon TP: The human gammaglutamyltransferase gene family. Hum Genet 2008, 123:321-332.

40. Lertratanangkoon K, Wu CJ, Savaraj N, Thomas ML: Alterations of DNA methylation by glutathione depletion. Cancer Lett 1997, 120:149-156.

41. Carl JW, Bai X-F: IL27: its roles in the induction and inhibition of inflammation. Int J Clin Exp Pathol 2008, 1:117-123.

42. Long J, Zhang X, Wen M, Kong Q, Lv Z, An Y, Wei X-Q: IL-35 overexpression increases apoptosis sensitivity and suppresses cell growth in human cancer cells. Biochem Biophys Res Commun 2013, 430:364-369.

43. Dou R, Deng Y, Huang L, Fu S, Tan S, Wang L, Lian L, Fang L, Fan X, Jin G, Liu H, Wang J: Multi-microarray identifies lower AQP9 expression in adjuvant chemotherapy nonresponders with stage III colorectal cancer. Cancer Lett 2013, 336:106-113.

44. Yu H-F, Zhao G, Ge Z-J, Wang D-R, Chen J, Zhang Y, Zha T-Z, Zhang K, Zhang M, Tan Y-F, Zhou S-J, Jiang C: High RIN1 expression is associated with poor prognosis in patients with gastric adenocarcinoma. Tumour Biol 2012, 33:1557-1563.

45. He H, Wu G, Liu H, Cheng Y, Yu Y, Wang Y, Liu Y: Low RIN1 Expression in HCC Is Associated With Tumor Invasion and Unfavorable Prognosis. Am J Clin Pathol 2013, 140:73-81.

46. Fang $P$, Zhao Z, Tian H, Zhang X: RIN1 exhibits oncogenic property to suppress apoptosis and its aberrant accumulation associates with poor prognosis in melanoma. Tumour Biol 2012, 33:1511-1518.

47. Shan G, Zhang Z, Chen Q, Yu X, Liu G, Kong C: Overexpression of RIN1 associates with tumor grade and progression in patients of bladder urothelial carcinoma. Tumour Biol 2012, 33:847-855.

48. Ashour N, Angulo JC, Andrés G, Alelú R, González-Corpas A, Toledo MV, Rodríguez-Barbero JM, López Jl, Sánchez-Chapado M, Ropero S: A DNA hypermethylation profile reveals new potential biomarkers for prostate cancer diagnosis and prognosis. Prostate 2014, 74:1171-1182.

49. Salhia B, Kiefer J, Ross JTD, Metapally R, Martinez RA, Johnson KN, DiPerna DM, Paquette KM, Jung S, Nasser S, Wallstrom G, Tembe W, Baker A, Carpten J, Resau J, Ryken T, Sibenaller Z, Petricoin EF, Liotta LA, Ramanathan RK, Berens ME, Tran NL: Integrated genomic and epigenomic analysis of breast cancer brain metastasis. PLOS One 2014, 9:e85448.

50. Roperch J-P, Incitti R, Forbin S, Bard F, Mansour H, Mesli F, Baumgaertner I, Brunetti F, Sobhani I: Aberrant methylation of NPY, PENK, and WIF1 as a promising marker for blood-based diagnosis of colorectal cancer. BMC Cancer 2013, 13:566.

51. Kishida Y, Natsume A, Kondo Y, Takeuchi I, An B, Okamoto Y, Shinjo K, Saito K, Ando H, Ohka F, Sekido Y, Wakabayashi T: Epigenetic subclassification of meningiomas based on genome-wide DNA methylation analyses. Carcinogenesis 2012, 33:436-441.

52. Chung W, Bondaruk J, Jelinek J, Lotan Y, Liang S, Czerniak B, Issa J-PJ: Detection of bladder cancer using novel DNA methylation biomarkers in urine sediments. Cancer Epidemiol Biomarkers Prev 2011, 20:1483-1491.

53. Chung J-H, Lee HJ, Kim B-H, Cho N-Y, Kang GH: DNA methylation profile during multistage progression of pulmonary adenocarcinomas. Virchows Arch 2011, 459:201-211.

54. Olkhov-Mitsel E, Van der Kwast T, Kron KJ, Ozcelik H, Briollais L, Massey C, Recker F, Kwiatkowski M, Fleshner NE, Diamandis EP, Zlotta AR, Bapat B: Quantitative DNA methylation analysis of genes coding for kallikreinrelated peptidases 6 and 10 as biomarkers for prostate cancer. Epigenetics 2012, 7:1037-1045.

55. Zhang $Y$, Wang $R$, Song $H$, Huang G, Yi J, Zheng Y, Wang J, Chen L: Methylation of multiple genes as a candidate biomarker in non-small cell lung cancer. Cancer Lett 2011, 303:21-28.

56. Worsham MJ, Chen KM, Meduri V, Nygren AOH, Errami A, Schouten JP, Benninger MS: Epigenetic events of disease progression in head and neck squamous cell carcinoma. Arch Otolaryngol Head Neck Surg 2006, 132:668-677.
57. Wang $L$, Jin HC, Wang X, Lam EKY, Zhang J, Bin, Liu X, Chan FKL, Si JM, Sung JJY: ZIC1 is downregulated through promoter hypermethylation in gastric cancer. Biochem Biophys Res Commun 2009, 379:959-963

58. Cheng YY, Kirschner MB, Cheng NC, Gattani S, Klebe S, Edelman JJB, Vallely MP, McCaughan BC, Jin HC, van Zandwijk N, Reid G: ZIC1 is silenced and has tumor suppressor function in malignant pleural mesothelioma. J Thorac Oncol 2013, 8:1317-1328.

59. Huang R-L, Gu F, Kirma NB, Ruan J, Chen C-L, Wang H-C, Liao Y-P, Chang C-C, Yu M-H, Pilrose JM, Thompson IM, Huang H-C, Huang TH-M, Lai H-C, Nephew KP: Comprehensive methylome analysis of ovarian tumors reveals hedgehog signaling pathway regulators as prognostic DNA methylation biomarkers. Epigenetics 2013, 8:624-634.

60. Milstein M, Mooser CK, Hu H, Fejzo M, Slamon D, Goodglick L, Dry S, Colicelli J: RIN1 is a breast tumor suppressor gene. Cancer Res 2007, 67:11510-11516.

61. Zhang Y-W, Zheng Y, Wang J-Z, Lu X-X, Wang Z, Chen L-B, Guan X-X, Tong J-D: Integrated analysis of DNA methylation and mRNA expression profiling reveals candidate genes associated with cisplatin resistance in non-small cell lung cancer. Epigenetics 2014, 9:896-909.

62. Wang J, Wang L, Zhang D, Fan Y, Jia Z, Qin P, Yu J, Zheng S, Yang F: Identification of potential serum biomarkers for Wilms tumor after excluding confounding effects of common systemic inflammatory factors. Mol Biol Rep 2012, 39:5095-5104.

63. Vermaat JS, van der Tweel I, Mehra N, Sleijfer S, Haanen JB, Roodhart JM, Engwegen JY, Korse CM, Langenberg MH, Kruit W, Groenewegen G, Giles $\mathrm{RH}$, Schellens $\mathrm{JH}$, Beijnen JH, Voest EE: Two-protein signature of novel serological markers apolipoprotein-A2 and serum amyloid alpha predicts prognosis in patients with metastatic renal cell cancer and improves the currently used prognostic survival models. Ann Oncol 2010, 21:1472-1481.

64. Paret C, Schön Z, Szponar A, Kovacs G: Inflammatory protein serum amyloid $A 1$ marks a subset of conventional renal cell carcinomas with fatal outcome. Eur Urol 2010, 57:859-866.

65. Grützmann R, Molnar B, Pilarsky C, Habermann JK, Schlag PM, Saeger HD, Miehlke S, Stolz T, Model F, Roblick UJ, Bruch H-P, Koch R, Liebenberg V, Devos T, Song X, Day RH, Sledziewski AZ, Lofton-Day C: Sensitive detection of colorectal cancer in peripheral blood by septin 9 DNA methylation assay. PLoS One 2008, 3:e3759.

66. deVos T, Tetzner R, Model F, Weiss G, Schuster M, Distler J, Steiger KV, Grützmann R, Pilarsky C, Habermann JK, Fleshner PR, Oubre BM, Day R, Sledziewski AZ, Lofton-Day C: Circulating methylated SEPT9 DNA in plasma is a biomarker for colorectal cancer. Clin Chem 2009, 55:1337-1346.

67. Marks LS, Fradet Y, Deras IL, Blase A, Mathis J, Aubin SMJ, Cancio AT, Desaulniers M, Ellis WJ, Rittenhouse H, Groskopf J: PCA3 molecular urine assay for prostate cancer in men undergoing repeat biopsy. Urology 2007, 69:532-535.

68. Deras IL, Aubin SMJ, Blase A, Day JR, Koo S, Partin AW, Ellis WJ, Marks LS, Fradet Y, Rittenhouse H, Groskopf J: PCA3: a molecular urine assay for predicting prostate biopsy outcome. J Urol 2008, 179:1587-1592.

69. Haese A, de la Taille A, van Poppel H, Marberger M, Stenzl A, Mulders PFA, Huland $\mathrm{H}$, Abbou C-C, Remzi M, Tinzl M, Feyerabend S, Stillebroer AB, van Gils MPMQ, Schalken JA: Clinical utility of the PCA3 urine assay in European men scheduled for repeat biopsy. Eur Urol 2008, 54:1081-1088.

70. Durand X, Moutereau S, Xylinas E, de la Taille A: Progensa ${ }^{\mathrm{TM}}$ PCA3 test for prostate cancer. Expert Rev Mol Diagn 2011, 11:137-144.

\section{doi:10.1186/s12916-014-0235-x}

Cite this article as: Lasseigne et al:: DNA methylation profiling reveals novel diagnostic biomarkers in renal cell carcinoma. BMC Medicine 2014 12:235. 